\title{
PERSONAS ANCIANAS: SALUD Y SOLEDAD
}

María Teresa Bazo

Universidad del País Vasco, Bilbao

RESUMEN. El presente artículo se enmarca en la sociología de la ancianidad. El proceso de envejecimiento en España es uno de los procesos sociales de mayor importancia. Las personas en nuestro país están llegando progresivamente a más edad, y la mayoría en buen estado relativo de salud. La salud en el presente artículo es una autoevaluación realizada por una muestra de ancianos/as de Bilbao. Las mujeres y grupos sociales de bajo estatus socioeconómico se autoperciben más negativamente. El sentimiento de soledad es la variable que muestra mayor asociación con la salud.

Los problemas de salud son más frecuentes con la edad. Las personas mayores representan un grupo de riesgo. Sin embargo, en todo el mundo desarrollado, principalmente, las personas están llegando no solamente a más edad, sino muchas de ellas en mejor estado de salud (Palmore, 1976; H. Cox, 1984: 343; J. A. Brody, 1982; B. Neugarten, 1988; V. W. Marshall, 1982). Por otro lado, la imagen de los ancianos/as como enfermos, incapaces de cuidar de sí mismos, de mantener una relación amorosa y de rendir un servicio a los demás, es bastante falsa ( $R$. Besdine, 1988). La salud es uno de los aspectos más importantes de la vida, y sobre todo en las vidas de las personas mayores, dada la influencia de esta variable en otras, como la percepción que se tiene de sí mismo/a y del mundo circundante. El estado de salud determina en qué actividades o tareas puede uno/a implicarse. Igualmente la presencia o ausencia de buena salud tiene que ver con la capa- 
cidad de mantener la independencia y autonomía personal. Esos son aspectos fundamentales en la vida de una persona de cualquier edad, por su influencia en la autoestima y la satisfacción general.

En el artículo se analiza el nivel de salud de la población anciana de Bilbao, a través de una encuesta realizada sobre una muestra de 412 personas de sesenta y cuatro y más años, proporcional por subgrupos de edad y género en cada uno de los 14 distritos del municipio. El estado de salud se refiere a la percepción que de la misma tienen los entrevistados/as. Asumiendo el concepto de salud definido en 1946 por la OMS como «no únicamente la ausencia de enfermedad, sino también como un estado de bienestar físico, psíquico y social», la medida de salud de la población anciana tiene un carácter subjetivo, sentido. Sin duda es también importante conocer el estado de salud objetiva de tal grupo de edad; una cierta aproximación puede suponer la declaración de los problemas realizada por los propios entrevistados/as, se supone que en muchos casos en base a los diagnósticos realizados por los médicos. El conocimiento de las percepciones de las personas es un aspecto fundamental. No se puede comprender la calidad psicológica de la vida de las personas, simplemente, a partir del conocimiento de las circunstancias en las que viven. Dado que la mente influye en gran medida en nuestra percepción del mundo, «si tratamos de explicar el sentido de bienestar de la población sobre la base de las circunstancias objetivas, no llegaremos a explicar la mayor parte de lo que pretendemos» (A. Campbell, 1981: 2).

En primer lugar el estudio tiene en cuenta si declaran tener o no problemas de salud. En segundo lugar, estudia de qué problemas se trata, agrupándolos según afecten a los diferentes sistemas o aparatos del cuerpo humano. En tercer lugar, se tiene en cuenta la percepción de las consecuencias negativas en el bienestar de tales problemas: es decir, en qué medida impiden al entrevistado/a realizar aquellas cosas que habitualmente desea poder hacer. Por último, se tiene en cuenta la capacidad declarada por el individuo para desplazarse a pie.

El 62 por 100 de las personas entrevistadas declara tener algún problema de salud, y un 36 por 100 de ellas que tal o tales problemas le impiden la realización de muchas de las actividades que desea realizar. Sumando las personas que dicen no sufrir problemas (aunque pueden tener alguna enfermedad o deterioro crónicos) a las personas que declarando padecerlos no les obstaculizan severamente (total, 324 individuos), resulta que el 79 por 100 de todos los entrevistados/as declara no tener incapacidades de importancia que les impidan proseguir sus actividades cotidianas. Si a estos resultados se añade que la gran mayoría de los entrevistados/as (93 por 100) declara poder desplazarse bien a pie (65 por 100) o con alguna dificultad ( 28 por 100), parece que el estado de sa'ud de los ancianos/as de Bilbao es en general relativamente bueno. Unicamente el 7 por 100 declara estar más o menos 
inmovilizado. Aunque los resultados no pueden ser estrictamente comparables, resulta interesante comprobar que los datos que $\mathrm{H}$. Cox aporta sobre la salud de los ancianos/as estadounidenses coinciden en buena medida con los datos de nuestra muestra. A pesar de la presencia de diferentes enfermedades crónicas, «aproximadamente el 80 por 100 de los ancianos/as estadounidenses no están seriamente incapacitados/as para llevar una vida plena y proseguir las actividades cotidianas normales» (H. Cox, 1984: 101).

Al analizar el estado de salud percibida de los ancianos/as de Bilbao, tomando como base el género (tabla 1), aparece que el 64 por 100 de las mujeres declara padecer problemas de salud, mientras que los varones lo declaran en el 58 por 100 de los casos. Las mujeres manifiestan más que los varones tener problemas de salud. Su percepción de la misma parece peor que la que tienen los varones; quizá por eso van más al médico, aunque luego sean ellas las que viven más tiempo. Otros estudios han detectado la misma tendencia (J. M. de Miguel, 1977: 120; 1985: 99). A. Campbell es uno de los autores que señalan cómo a cualquier edad las mujeres se muestran más proclives a declarar sus problemas de salud. Teniendo en cuenta la edad, aparece claramente una relación inversa entre edad y estado de salud percibida. Todos los estudios de salud muestran un aumento de la enfermedad con la edad (Campbell, 1981): a más edad, corresponde peor salud. En la tercera categoría se incrementa la peor percepción para mejorar en la cuarta. Pudiera ser que a partir de los setenta y cuatro años se sufriera un «bajón» en la salud, seguido de un cierto estacionamiento de la misma en el siguiente lustro, que llevase a los ancianos/as a sentirse relativamente mejor, para volver a caer en picado en el último tramo de sus vidas. No obstante, aún en esos últimos años, una no despreciable cuarta parte de ellos/as considera que no tiene problemas.

Pero hay otra serie de variables, muy a tener en cuenta al analizar el estado de salud. Tomando como base el estado civil y prescindiendo de los divorciados/as por su escasa representatividad (menos del 1 por $100 \mathrm{del}$ total de la muestra), aparecen los solteros/as como los menos enfermos/as o como los más optimistas en la percepción de su salud. Resulta destacable la ausencia de diferencia entre casados/as y viudos/as. La categoría más diferenciada y con percepción más positiva sería la de los solteros/as en su conjunto. Una posible explicación estaría en que la variable estado de salud está dicotomizada y que por el estado civil la población se reparte equitativamente entre casados/as (45 por 100) y viudos/as (44 por 100), quedando en la categoría de solteros únicamente el 10 por 100.

Si se observan los datos relativos a la ocupación principal (tabla 2), es de destacar la mejor percepción respecto a la categoría siguiente de los empresarios/as, directores, cuadros superiores, altos funcionarios y profesionales liberales. La categoría, que aparece en segundo lugar como la más saludable, corresponde a los comerciantes y empresarios sin asalariados 
TABLA 1

Nivel de salud percibida por género, edad y estado civil (En porcentajes)

\begin{tabular}{|c|c|c|c|c|c|c|c|c|c|c|c|}
\hline \multirow[b]{2}{*}{ Nivel de salud } & \multirow[b]{2}{*}{ Total } & \multicolumn{2}{|c|}{ GENERO } & \multicolumn{5}{|c|}{ GRUPOS DE EDAD, EN AÑOS } & \multicolumn{3}{|c|}{ ESTADO CIVIL } \\
\hline & & Varones & Mujeres & $65-69$ & $70-74$ & 75.79 & 80.84 & 85 y más & Soltero/a & Casado/a & Viudo/a \\
\hline $\begin{array}{lllllll}\text { Enfermos } & \text { as } & \ldots & \ldots & \ldots & \ldots & \ldots \\
\text { Sanos/as } & \ldots & \ldots & \ldots & \ldots & \ldots & \ldots \\
\text { NS/NC } & \ldots & \ldots & \ldots & \ldots & \ldots & \ldots\end{array}$ & $\begin{array}{r}61 \\
38 \\
1\end{array}$ & $\begin{array}{l}58 \\
42 \\
-\end{array}$ & $\begin{array}{l}64 \\
36 \\
-\end{array}$ & $\begin{array}{r}57 \\
42 \\
1\end{array}$ & $\begin{array}{l}59 \\
41 \\
-\end{array}$ & $\begin{array}{r}64 \\
35 \\
1\end{array}$ & $\begin{array}{r}61 \\
37 \\
2\end{array}$ & $\begin{array}{l}74 \\
26 \\
-\end{array}$ & $\begin{array}{l}58 \\
42 \\
-\end{array}$ & $\begin{array}{l}62 \\
38 \\
-\end{array}$ & $\begin{array}{r}61 \\
38 \\
1\end{array}$ \\
\hline $\begin{array}{rrrrrr}\text { Total. } & \ldots & \ldots & \ldots & \ldots & \ldots \\
\text { Número de } & \operatorname{casos} & \ldots & \ldots & \ldots\end{array}$ & $\begin{array}{c}100 \\
(410)\end{array}$ & (163) & (247) & (114) & $(108)$ & (89) & (62) & (39) & (40) & $(186)$ & (181) \\
\hline
\end{tabular}

FuenTE: Encuesta de Ancianos/as de Bilbao 1988. 


\section{TABLA 2}

Nivel de salud percibida por ocupación

(En porcentajes)

\begin{tabular}{|c|c|c|c|c|c|c|c|c|}
\hline \multirow[b]{2}{*}{ Nivel de salud } & \multirow[b]{2}{*}{ Total } & \multicolumn{7}{|c|}{ CATEGORIAS OCUPACIONALES } \\
\hline & & $\begin{array}{l}\text { Amas } \\
\text { de } \\
\text { casa }\end{array}$ & $\begin{array}{l}\text { Empresa- } \\
\text { rios/as, } \\
\text { cuadros } \\
\text { superiores } \\
\text { allos } \\
\text { funcionarios }\end{array}$ & $\begin{array}{c}\text { Emplea- } \\
\text { dos/as, } \\
\text { cuadros } \\
\text { medios } \\
\text { funcionarios }\end{array}$ & $\begin{array}{l}\text { Trabajadores } \\
\text { por cuenta } \\
\text { propia }\end{array}$ & $\begin{array}{l}\text { Obreros/as } \\
\text { especiali- } \\
\text { zados }\end{array}$ & $\begin{array}{l}\text { Obreros/as } \\
\text { sin } \\
\text { especializar }\end{array}$ & $N S / N C$ \\
\hline 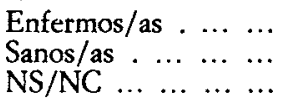 & $\begin{array}{r}61 \\
38 \\
1\end{array}$ & $\begin{array}{l}64 \\
36 \\
-\end{array}$ & $\begin{array}{l}36 \\
64 \\
-\end{array}$ & $\begin{array}{l}56 \\
44 \\
-\end{array}$ & $\begin{array}{l}48 \\
52 \\
-\end{array}$ & $\begin{array}{r}69 \\
30 \\
1\end{array}$ & $\begin{array}{r}65 \\
33 \\
2\end{array}$ & $\begin{array}{l}50 \\
50 \\
-\end{array}$ \\
\hline $\begin{array}{rlll}\text { Total } & \ldots & \ldots & \ldots \\
\text { Número de } & & & \\
\text { casos } & \ldots\end{array}$ & $\begin{array}{c}100 \\
(412)\end{array}$ & $(166)$ & (14) & $(48)$ & $(40)$ & $(73)$ & (69) & (2) \\
\hline
\end{tabular}

FuENTE: Encuesta de Ancianos/as de Bilbao 1988. 
y trabajadores por cuenta propia. Por encima de la media aparece también la categoría de cuadros medios, empleados y funcionarios en general. Por debajo de la media aparecen en primer lugar las amas de casa, seguidas en su peor estado de salud por los obreros/as sin cualificación y personal de servicio (compuesto en un 51 por 100 por mujeres) y de los obreros/as cualificados, capataces y personal de servicio. Las categorías ocupacionales de más baja cualificación son igualmente las que peor percepción tienen de su salud. Existe una relación directa entre ocupación y salud, ya que las categorías ocupacionales de mayor cualificación y personas que tienen o han tenido su propio pequeño negocio son las que perciben más favorablemente su salud. Parece igualmente que existe una relación entre medidas objetivas y subjetivas. Exceptuando a las amas de casas, ya que son todas mujeres y éstas viven más que los varones, aparece una relación entre la percepción de los diferentes grupos profesionales y los datos objetivos conocidos sobre morbilidad y mortalidad diferenciales (J. M. de Miguel, 1977, 1985; C. Cabirol, 1981: 96).

La relación de los ingresos con la salud (tabla 3) no aparece tan clara, aunque son las personas con recursos más altos las que tienen mejor percepción de su salud. Otros estudios destacan cómo las personas de ingresos más bajos son más propensas a declarar problemas de salud que la gente con ingresos más altos. Incluso se señala cómo en general entre las personas ancianas, aun dándose un incremento de los problemas por la edad, si se dispone de ingresos suficientes se padece en menor medida problemas de salud, lo que deja ver la influencia sobre la misma del estatus económico (R. G. Grandall, 1980: 15; J. Williamson, 1980: 231). Según señala $\mathrm{J}$. Williamson, es difícil medir los efectos en la salud de las enfermedades crónicas, junto con los bajos ingresos, la soledad o la falta de amistades, pero la creciente evidencia de la influencia del estrés en la enfermedad y en la influencia mutua de la mente y el cuerpo pone de manifiesto que tales factores juegan un importante papel en los problemas de salud de las personas mayores.

La gran mayoría de los ancianos/as de Bilbao declara encontrarse en un relativo buen estado de salud. Sin embargo, existen algunas personas que declaran tener problemas. El grupo en peor estado de salud percibida está compuesto en mayor proporción por mujeres que por varones, por personas casadas y viudas que por personas solteras, por las más ancianas que por las más jóvenes, por las categorías profesionales de menos cualificación que por las más cualificadas, por las de menos ingresos que por las de más ingresos.

En cuanto a las consecuencias que los problemas de salud tienen sobre la vida cotidiana de quienes dicen suftirlos, el 37 por 100 dice que le impiden realizar muchas cosas, el 30 por 100 algunas cosas, el 15 por 100 unas pocas cosas, y el 18 por 100 ninguna cosa. Es importante señalar la apro- 


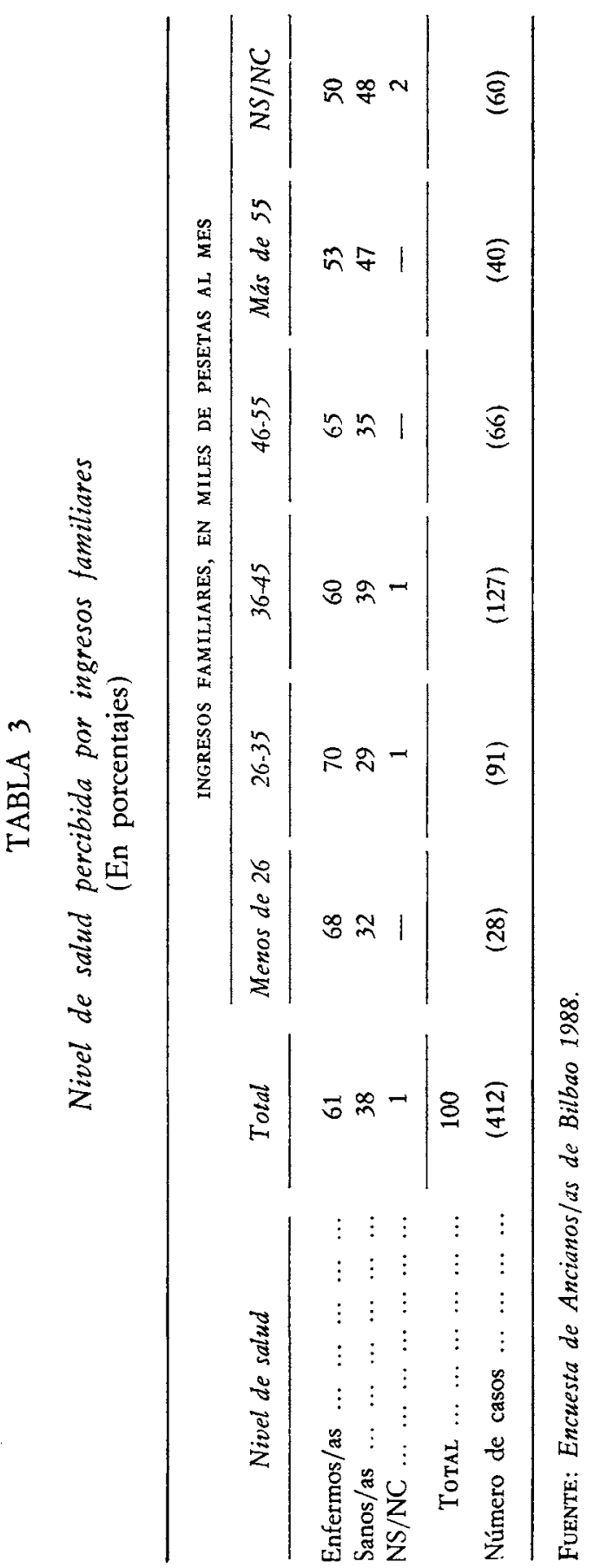


ximación del porcentaje que declara padecer muchos inconvenientes (37 por 100), con la proporción señalada por Campbell de constituir aproximadamente un 30 por 100 entre las personas mayores de setenta y cinco años en Estados Unidos. En el presente estudio, la proporción de ese subgrupo es del 26 por 100. Las diferencias por género son menos importantes, aunque aparecen las mujeres como más pesimistas, destacando la diferencia existente en la percepción más positiva de las consecuencias. Un menor porcentaje de mujeres (15 por 100) que de varones (22 por 100) cree que no le afectan nada sus problemas. Los varones, además de declararse menos enfermos que las mujeres, aquellos que se declaran enfermos son algo más optimistas que las mujeres respecto a las consecuencias negativas de sus problemas de salud. Hay que recordar que la mujer suele aparecer más propensa a declarar sus enfermedades y a considerarse enferma que el varón.

Tomando como base el estado civil en la percepción de las consecuencias negativas de los problemas de salud, resulta que son las personas solteras las que perciben su situación algo más negativamente (22 por 100), siendo las casadas las que tienen mejor percepción (15 por 100). Las viudas mantienen una posición intermedia (18 por 100). Si las personas solteras aparecían anteriormente como las menos enfermas, aquellas que se declaran como tales aparecen como las más pesimistas, incluso más que las viudas. Son las que peor percepción tienen de las consecuencias de sus problemas de salud. Campbell sugiere cómo la falta de apoyo social íntimo que el matrimonio proporciona podría explicar, aunque sea parcialmente, los mayores porcentajes de malestar declarados entre los/as solteros. Otros autores consideran el matrimonio como una fuerza positiva para el mantenimiento de la salud (W. McKain, 1969). Los grupos aparecen más diferenciados por estado civil en la percepción de las consecuencias de la enfermedad que en la salud percibida. Debe tenerse en cuenta la alta proporción de mujeres entre las personas viudas ( 80 por 100 de todas ellas), así como la alta proporción de ellas también entre las personas solteras ( 77 por 100). Las mujeres muestran, además de peor salud percibida, peor percepción de sus consecuencias que el varón.

Si se analiza la edad, la percepción más positiva va unida al menor número de años, ya que el porcentaje de quienes declaran sufrir muchos inconvenientes pasa del 34 por 100 en las personas más jóvenes, al 45 por 100 en las más ancianas. Existe una relación inversa también en este caso entre edad y percepción de las consecuencias de la enfermedad. Teniendo en cuenta la ocupación, no aparece una relación tan clara con la salud en la percepción de las consecuencias de la enfermedad como aparece con el estado de salud percibida. Dos categorías de entre ellas, la clase alta (25 por 100) y los/as trabajadores «de cuello blanco» (25 por 100 ) aparecen como las más positivas, seguidas, aunque a distancia, de los obreros/as sin cualificar (30 por 100) y los/as trabajadores independientes ( 37 por 100 ). En penúltimo lugar están 
las amas de casa ( 39 por 100), y en último lugar, la categoría correspondiente a los obreros/as cualificados (46 por 100). Se aprecia, pues, una cierta tendencia entre las personas que se sienten enfermas, a percibirse mejor aquellas que pertenecen a categorías ocupacionales más cualificadas. Con la variable ingresos no se halla una clara relación directa, aunque la tendencia apunta a una mejor percepción de quienes obtienen más ingresos, siendo las dos categorías de más bajos ingresos, compuestas en más de cuatro quintas partes por mujeres ( 85 y 87 por 100 , respectivamente), las que manifiestan una percepción más negativa de sus problemas de salud.

La percepción de las consecuencias de la enfermedad se ajusta al siguiente perfil: experimentan peor percepción las mujeres, las personas solteras y viudas, las personas de más edad, las categorías ocupacionales de más baja cualificación, y las personas que perciben menos ingresos. El perfil de los grupos más pesimistas o de peor percepción de las consecuencias de sus problemas de salud coincide en buena medida (excepto en el estado civil) con el trazado al resumir la percepción de los ancianos/as de Bilbao como sanos o enfermos. En general, los grupos que presentan un peor estado de salud vuelven a aparecer también entre los que se declaran más afectados por los problemas. El caso de las mujeres requiere un análisis más pormenorizado.

En cuanto a las expectativas sobre su salud que muestran las personas entrevistadas, en su conjunto no aparecen grandes diferencias. Tienden a concentrarse las respuestas en la posición intermedia: el 78 por 100 espera seguir igual de salud en las próximas semanas; un 10 por 100 espera mejorar, y un 12 por 100 teme empeorar. Por género no se aprecian diferencias. Por edad, el grupo de sesenta y cinco-sesenta y nueve años es el más optimista (16 por 100 de ellos espera mejorar), apareciendo el grupo de ochenta y cinco y más años como el más pesimista (espera empeorar el 26 por 100). Por estado civil, los solteros/as aparecen más «conservadores» (el 92 por 100 espera seguir igual) y los viudos/as algo más optimistas que los casados/as (esperan mejorar el 13 y el 9 por 100 , respectivamente). Por ingresos no se aprecia una clara relación, aunque quienes más cobran aparecen más optimistas. En cuanto a la ocupación, parece apreciarse más optimismo y «conservadurismo» en la clase alta, empleados/as (trabajadores «de cuello blanco») e independientes, apareciendo más pesimistas los obreros/as cualificados. H. Cox (1984) considera que no se ha estudiado atentamente la psicología social de la enfermedad. Desde la perspectiva del interaccionismo simbólico, gran parte de la conducta de la gente, así como su autoconcepto, estarían determinados por los roles que asumen y las expectativas de los otros en función de esos mismos roles. Desde este punto de vista se entiende que hasta cierto punto un problema de los ancianos/as es que a menudo se espera de ellos/as que asuman el rol de enfermos, seniles y débiles, mucho antes incluso de que fisiológicamente lleguen a tal estado. Del mismo modo aquellas personas que en sus últimos años caen enfermas puede que la' familia, el 
personal sanitario y, finalmente, las propias personas no esperen ya su recuperación.

Pero ¿cuáles y cuántos son esos problemas que afectan a los entrevistados? El 62 por 100 de la muestra declara tener al menos un problema de salud; de todos éstos, un 40 por 100 declara tener, además, un segundo problema; y un 14 por 100 declara tener, al menos, un tercer problema más. El total de declaraciones de problemas (los que declaran padecer uno, los que declaran dos, los que declaran tres, es de 349). Afecciones que se reparten como sigue, por orden de importancia y agrupadas en los sistemas y aparatos del cuerpo humano:

\begin{tabular}{|c|c|}
\hline & Porcentajes \\
\hline $\begin{array}{llllllll}\text { Aparato osteo-articular } & \ldots & \ldots & \ldots & \ldots & \ldots \\
\text { Aparato circulatorio } & \ldots & \ldots & \ldots & \ldots & \ldots & \ldots \\
\text { Aparato respiratorio } & \ldots & \ldots & \ldots & \ldots & \ldots & \ldots \\
\text { Sistema endocrino } & \ldots & \ldots & \ldots & \ldots & \ldots & \ldots \\
\text { Aparato digestivo } & \ldots & \ldots & \ldots & \ldots & \ldots & \ldots \\
\text { Sistema audiovisual } & \ldots & \ldots & \ldots & \ldots & \ldots & \ldots \\
\text { Sistema nervioso } & \ldots & \ldots & \ldots & \ldots & \ldots & \ldots & \ldots \\
\text { Aparato urogenital } & \ldots & \ldots & \ldots & \ldots & \ldots & \ldots \\
\text { Inespecificas y otras } & \ldots & \ldots & \ldots & \ldots & \ldots & \ldots\end{array}$ & $\begin{array}{r}31 \\
17 \\
11 \\
10 \\
8 \\
8 \\
4 \\
3 \\
8\end{array}$ \\
\hline
\end{tabular}

Todos aquellos grupos peor posicionados en el estado de salud, o son mujeres o están integrados en su mayoría por mujeres. ¿Podría decirse que el hecho de ser mujer va a condicionar la percepción de la salud y el sentimiento de su carencia a las personas ancianas? Sin embargo, aunque enfermas, las mujeres viven más tiempo, se mueren más tarde que los varones, y cada vez incluso con más edad. ¿Se trataría únicamente de un condicionamiento cultural que obraría en las mujeres, haciéndoles sentirse menos inhibidas que los varones a la hora de declararse como enfermas? No es un tema suficientemente estudiado. Ciertos autores se preguntan si las mujeres están objetivamente más enfermas que los varones, o si lo que ocurse es que manifiestan más los síntomas (I. Alonso, 1977: 109).. En su conjunto no son muchas las personas ancianas que se declaran seriamente afectadas por sus achaques y enfermedades, por lo que en los grupos que así lo manifiestan obran sin duda factores de tipo diverso. Existen factores biológicos y fisiológicos: personas de más edad (con riesgo, por tanto, de peor salud) y otras «objetivamente» más enfermas; de carácter psicológico y personal: carácter de ciertas personas, rasgos de personalidad, hipocondríacos incluso; y factores sociales, porque existe una morbilidad y mortalidad diferenciales según el estatus socioeconómico.

Es posib.e que sea la soledad la que hace que ciertas personas, según el 
perfil trazado anteriormente, sientan más achaques y perciban de forma más angustiosa sus problemas de salud que las personas que detentan otros rasgos y características. La soledad aparece como un correlato de la vejez femenina. Al analizar el estado civil se hizo referencia al matrimonio como fuente de salud. Las tablas siguientes presentan las respuestas obtenidas a la pregunta «tiene usted sentimiento de soledad a lo largo del dia» al tener en cuenta las variables género, salud, estado civil, edad, profesión e ingresos. Un 69 por 100 de los ancianos/as de Bilbao no se siente solo nunca, aunque el resto tiene un cierto o intenso sentimiento de soledad. ¿Quiénes son esos/as que se sienten más solos? Por género (tabla 4), de nuevo son las mujeres; ellas, que se sienten más enfermas, se sienten también más solas. Teniendo en cuenta la edad, aparece cómo los dos grupos más jóvenes se declaran los menos solos. Los pertenecientes al siguiente decenio setenta y cinco a ochenta y cuatro años de edad, manifiestan sentirse más solos que el resto de los grupos de edad. Los/as más ancianos, los que han sobrepasado los ochenta y cuatro, tienen el porcentaje mayor (13 por 100) de intensidad de soledad, aunque el porcentaje intermedio es el más bajo de todos los grupos y el de ausencia de sentimiento es igual que el del grupo más joven ( 72 por 100). En este grupo se da una gran mayoría (como en todos) de personas que no se sienten solas, pero una minoría que se siente más que los demás grupos. El geriatra Claude Cabirol señala: «Hemos visto que la naturaleza y consecuencias de las enfermedades cambian con la edad y que el aislamiento y la pérdida de autonomía son los estigmas propios de la cuarta edad» (C. Cabirol, 1981: 114).

Ese grupo de ancianos/as de más edad (ochenta y cinco y más años), dice vivir a solas o con el cónyuge en el 23 por 100 de los casos, pero únicamente el 13 por 100 tiene cónyuge. Así, pues, aunque es con mucho el grupo que más vive en compañía de otras personas, de hijos principalmente ( 77 por 100 ), sin embargo puede que sea de entre ese 23 por 100 de personas (mujeres en el 67 por 100 de los casos) que viven solas o con el cónyuge posiblemente mayor que ellas, las que experimentan más la soledad, así como un conjunto de pérdidas y problemas acumulados. No parece que la afirmación de Cabirol sobre el aislamiento de la cuarta edad sea cierto como generalización en los ancianos/as de Bilbao. Incluso es, y con gran diferencia del resto, quienes declaran recibir más visitas de sus hijos/as (75 por 100) que las que ellos/as mismos les hacen ( 3 por 100). Pero también es cierto que la acumulación de circunstancias negativas puede hacerles sentirse más solos/as, teniendo en cuenta que el sentimiento de soledad no se corresponde siempre (ni simplemente) con el aislamiento social. En cuanto al estado civil, las personas viudas, seguidas de las solteras, quedan fuertemente discriminadas con respecto a las casadas por la variable soledad. La presencia del cónyuge contribuye a no experimentar soledad, e incluso cuando se experimenta es menos intensa. 
TABLA 4

Frecuencia de los sentimientos de soledad experimentados

a lo largo del día por género, edad y estado civil

(En porcentajes)

\begin{tabular}{|c|c|c|c|c|c|c|c|c|c|c|c|}
\hline \multirow[b]{2}{*}{ Sentimiento de soledad } & \multirow[b]{2}{*}{ Total } & \multicolumn{2}{|c|}{ GENERO } & \multicolumn{5}{|c|}{ GRUPOS DE EDAD, EN AÑOS } & \multicolumn{3}{|c|}{ ESTADO CIVIL } \\
\hline & & Varones & Mujeres & $65-69$ & $70-74$ & $75-79$ & $80-84$ & 85 y más & Soltero/a & Casado/a & Viudo/a \\
\hline $\begin{array}{lllll}\text { Muchas veces } & \ldots & \ldots & \ldots & \ldots \\
\text { Algunas veces } & \ldots & \ldots & \ldots & \ldots \\
\text { Nunca o casi } & \text { nunca } & \ldots & \ldots\end{array}$ & $\begin{array}{r}8 \\
23 \\
69\end{array}$ & $\begin{array}{r}6 \\
17 \\
77\end{array}$ & $\begin{array}{r}5 \\
27 \\
44\end{array}$ & $\begin{array}{r}5 \\
23 \\
72\end{array}$ & $\begin{array}{r}5 \\
20 \\
75\end{array}$ & $\begin{array}{l}10 \\
27 \\
63\end{array}$ & $\begin{array}{l}11 \\
29 \\
60\end{array}$ & $\begin{array}{l}13 \\
15 \\
72\end{array}$ & $\begin{array}{r}7 \\
28 \\
65\end{array}$ & $\begin{array}{r}3 \\
16 \\
81\end{array}$ & $\begin{array}{l}12 \\
30 \\
58\end{array}$ \\
\hline $\begin{array}{rrrrrr}\text { Toral. } & \ldots & \ldots & \ldots & \ldots & \ldots \\
\text { Número de } & & & & & \\
\text { casos } & \ldots & \ldots & \ldots\end{array}$ & $\begin{array}{c}100 \\
(409)\end{array}$ & (162) & $(247)$ & (114) & (107) & $(89)$ & $(62)$ & (39) & $(40)$ & (185) & $(181)$ \\
\hline
\end{tabular}

Fuente: Encuesta de Ancianos/as de Bilbao 1988. 
Con respecto a la ocupación (tabla 5), se observa que a un nivel más alto en la escala ocupacional, corresponde un menor sentimiento de soledad; existe una clara relación inversa entre ambas variables; destacan los/as trabajadores manuales y amas de casa como los grupos que experimentan más soledad. De nuevo aparece el estilo de vida como telón de fondo interpretativo, como concepto fundamental en la explicación de los diferentes comportamientos, sentimientos y actitudes propios del heterogéneo colectivo llamado «tercera edad». Respecto a los ingresos (tabla 6) ocurre lo mismo, que se sienten más solos/as quienes disponen de menos medios económicos; soledad e ingresos se asocian inversamente. La diferencia entre enfermos/as y sanos/as son menores, pero a mayor nivel de salud se aprecia una menor soledad. Los grupos que se sienten más solos, cuyos porcentajes de percep. ción positiva quedan por debajo de la media, por orden de mayor a menor soledad percibida, son: los/as de ingresos más bajos (86 por 100 son mujeres); los viudos/as ( 81 por 100 son mujeres); los/as de más edad ( 65 por 100 mujeres); los que se sienten enfermos ( 63 por 100 mujeres): y sobre todo las mujeres. También se observa la soledad afectando más a las amas de casa; los solteros/as ( 77 por 100 mujeres); los obreros/as no cualificados y personal de servicio ( 51 por 100 mujeres); los obreros/as cualificados (15 por 100 mujeres).

De nuevo el contingente femenino aparece como abrumadoramente mayoritario en casi todos los grupos. Al analizar la salud percibida con las demás variables, aparece el peso del componente femenino en aquellos grupos que se perciben como más enfermos. Al tratar de ver si la soledad puede inducir a las personas de esos grupos, principalmente mujeres, a sentirse más enfermas, las variables analizadas (género, salud, estado civil, edad, ocupación e ingresos), resulta que discriminan de forma clara a la población en grupos que experimentan mayor o menor soledad, y de nuevo los grupos resultantes se identifican con los que experimentan peor salud.

¿Son los grupos que aparecen como más enfermos los que también se sienten más solos? ¿O viceversa? Resulta difícil saber cuál es la variable dependiente y cuál la independiente. Incluso en la percepción del propio estado de salud no influye una sola variable, sino toda una constelación de variables: 1) de carácter biodemográfico: las personas que llegan a más viejas (más mujeres que varones) corren el riesgo de hacerlo en peor estado de salud y, además, sin pareja; 2) de carácter cultural: educación de la mujer, más permisiva con la expresión de ciertos sentimientos, aunque más represiva de su autorrealización personal; 3) de carácter socioeconómico: la mayoría subsiste en gran medida con exiguas pensiones. Es de destacar que si la variable ingresos no muestra un carácter claramente discriminatorio con la variable salud y sus consecuencias, sí resulta discriminatoria con la variable soledad, observándose una relación inversa entre ambas.

Los ancianos/as no constituyen un grupo homogéneo. Otros autores, ha- 


\section{TABLA 5}

Frecuencia de los sentimientos de soledad experimentados

a lo largo del día por ocupación

(En porcentajes)

\begin{tabular}{|c|c|c|c|c|c|c|c|c|}
\hline \multirow[b]{2}{*}{$\begin{array}{c}\text { Sentimiento } \\
\text { de soledad }\end{array}$} & \multirow[b]{2}{*}{ Total } & \multicolumn{6}{|c|}{ CATEGORIAS OCUPACIONALES } & \multirow[b]{2}{*}{$N S / N C$} \\
\hline & & $\begin{array}{l}\text { Amas } \\
\text { de } \\
\text { casa }\end{array}$ & $\begin{array}{c}\text { Empresa- } \\
\text { rios/as, } \\
\text { cuadros } \\
\text { superiores } \\
\text { altos } \\
\text { funcionarios }\end{array}$ & $\begin{array}{c}\text { Emplea- } \\
\text { dos/as, } \\
\text { cuadros } \\
\text { medios } \\
\text { funcionarios }\end{array}$ & $\begin{array}{l}\text { Trabajadores } \\
\text { por cuenta } \\
\text { propia }\end{array}$ & $\begin{array}{l}\text { Obreros/as } \\
\text { especiali- } \\
\text { zados }\end{array}$ & $\begin{array}{l}\text { Obreros/as } \\
\text { sin } \\
\text { especializar }\end{array}$ & \\
\hline $\begin{array}{lll}\text { Muchas veces } & \ldots & \ldots \\
\text { Algunas veces } & \ldots & \ldots \\
\text { Nuca o casi nunca } & \ldots\end{array}$ & $\begin{array}{r}8 \\
23 \\
69\end{array}$ & $\begin{array}{r}9 \\
28 \\
63\end{array}$ & $\begin{array}{l}\overline{14} \\
86\end{array}$ & $\begin{array}{r}2 \\
15 \\
83\end{array}$ & $\begin{array}{r}2 \\
8 \\
90\end{array}$ & $\begin{array}{r}7 \\
24 \\
69\end{array}$ & $\begin{array}{l}14 \\
25 \\
61\end{array}$ & $\overline{100}$ \\
\hline $\begin{array}{r}\text { Total } \ldots \ldots \ldots \\
\text { Número de casos } \ldots\end{array}$ & $\begin{array}{c}100 \\
(411)\end{array}$ & $(166)$ & (14) & $(48)$ & $(40)$ & $(72)$ & (69) & (2) \\
\hline
\end{tabular}

Fuente: Encuesta de Ancianos/as de Bilbao 1988. 


\section{TABLA 6}

Frecuencia de los sentimientos de soledad experimentados a lo largo del día por ingresos familiares, y nivel de salud

\section{(En porcentajes)}

\begin{tabular}{|c|c|c|c|c|c|c|c|c|c|}
\hline \multirow{2}{*}{$\begin{array}{l}\text { Sentimiento } \\
\text { de soledad }\end{array}$} & \multirow[b]{2}{*}{ Total } & \multicolumn{4}{|c|}{ INGRESOS FAMILIARES, E } & \multicolumn{2}{|c|}{ MILES DE PESETAS AL ME } & \multirow[b]{2}{*}{ Enfermo/a } & \multirow[b]{2}{*}{ Sano/a } \\
\hline & & Menos de 26 & $26-35$ & $36-45$ & $46-55$ & Más de 55 & $N S / N C$ & & \\
\hline Muchas veces .... ... & 8 & 7 & 13 & 9 & 3 & 2 & 5 & 11 & 3 \\
\hline Algunas veces $\ldots \ldots$ & 23 & 36 & 31 & 21 & 18 & 15 & 20 & 25 & 19 \\
\hline Nunca o casi nunca ... & 69 & 57 & 56 & 69 & 79 & 83 & 75 & 64 & 78 \\
\hline Total $\ldots \ldots \ldots$ & 100 & & & & & & & & \\
\hline Número de casos ... & $(411)$ & (28) & (91) & (127) & $(66)$ & (40) & $(60)$ & (252) & $(156)$ \\
\hline
\end{tabular}

FuEnTE: Encuesta de Ancianos/as de Bilbao 1988. 
ciendo referencia a las condiciones de vida de los ancianos, insisten en las diferencias que marca un estilo de vida que depende de la profesión ejercida, de la naturaleza de los ingresos y del tipo de actividades sociales: «Se podría así describir todo tipo de ancianidades, de tal manera se agrandan las desigualdades con la edad. Las estadísticas dicen incluso que en relación con el conjunto de la población, las desigualdades referidas a la vida material se doblan después de los sesenta y cinco años» (C. Cabirol, 1981: 115). Existe un proceso de somatización en ciertas personas como los/as trabajadores en cadena que les lleva a convertir en enfermedades orgánicas los problemas surgidos en un trabajo alienante y represor de su necesidad de creatividad y responsabilidad. Las mujeres, por su parte, isienten que han perdido sus roles de esposa y madre sobre los que habían edificado en gran medida tanto el sentido de su vida como el de su propia identidad como personas? ¿Logran llenar ese vacío? Con el fin de profundizar en el análisis se ha procedido a un nuevo tratamiento de los datos realizando una neutralización de variables a fin de evitar las influencias de unas sobre otras. Se trata de ver la posible relación existente entre salud y género controlando la edad, el estado civil, la ocupación, los ingresos y la soledad.

\section{Salud y soledad}

Las diferencias en cuanto a la percepción de la salud en todos los grupos de edad entre varones y mujeres no son importantes prescindiendo del influjo de la edad (tabla 7). No parece que el género discrimine de forma sensible a las personas ancianas. Los varones, que van sintiéndose ligeramente peor de salud conforme envejecen, experimentan de forma notoria una mejor percepción de sus problemas de salud en el grupo de ochenta y cinco y más años. Las mujeres, que también se sienten peor con la edad, no experimentan la súbita mejoría de los varones de ochenta a ochenta y cuatro años; continúan la misma tendencia. negativa, aunque las de más de ochenta y cinco tienen también la peor percepción.

Al controlar la variable estado civil (tabla 8 ), es preciso tener en cuenta la menor representatividad del conjunto de las personas solteras, sobre todo de los varones (nueve personas). Entre todas las personas casadas, la diferencia en la salud percibida entre varones y mujeres es pequeña; sin embargo, se acrecienta algo entre las personas viudas, manifestando peor percepción las mujeres. Sin embargo, no existen diferencias entre mujeres solteras, casadas o viudas en cuanto a la percepción de su salud. En las mujeres, el estado civil no parece ejercer influencia sobre su salud percibida. Tampoco los varones muestran diferencias notables por estado civil, exceptuando los solteros, que son minoritarios, aunque los viudos parecen sentirse algo mejor que los casados. Puede decirse que neutralizando la variable estado civil, las 


\section{TABLA 8}

Relación entre salud y género, controlando por el estado civil (En porcentajes)

PERSONAS SEGUN EL ESTADO CIVIL

\begin{tabular}{|c|c|c|c|c|c|c|c|c|}
\hline \multicolumn{3}{|c|}{ Solteros/as } & \multicolumn{3}{|c|}{ Casados/as } & \multicolumn{3}{|c|}{ Viudos/as } \\
\hline Total & Varones & Mujeres & Totall & Varones & Mujeres & Total & Varones & Mujeres \\
\hline 56 & 33 & 63 & 62 & 61 & 64 & 62 & 54 & 64 \\
\hline 44 & 67 & 37 & 38 & 39 & 36 & 38 & 46 & 36 \\
\hline 100 & & & 100 & & & 100 & & \\
\hline (39) & (9) & (30) & $(185)$ & (118) & (67) & (181) & (35) & $(146)$ \\
\hline
\end{tabular}

FUente: Encuesta de Ancianos/as de Bilbao 1988. 
diferencias entre las personas en su salud percibida no son importantes; aparece más asociada la salud con el género que con la edad.

Controlando por la ocupación (tabla 9), los varones muestran siempre mejor percepción que las mujeres. Las mayores diferencias por género en cuanto a la percepción de la salud, se aprecian entre los/as autónomos y obreros/as sin especializar. Sin embargo, apenas existen diferencias entre los/as cuadros medios y obreros/as especializados. Los varones se sienten mejor de salud si pertenecen a la clase alta o si son empleados (trabajadores "de cuello blanco»), peor si son obreros sin cualificar y peor que ninguno si son obreros especializados. De nuevo aparecen los de esta categoría ocupacional como afectados en su salud, ya jubilados, por el tipo de trabajo desarrollado en su vida activa. Las mujeres se sienten mejor como trabajadoras por cuenta propia y empleadas de oficina, algo peor como amas de casa, y francamente mal como obreras sin especializar y como obreras cualificadas, donde se observan los porcentajes más altos de enfermas. Parece que ser varón o mujer influye en las diferentes percepciones de la salud, según de qué ocupación se trate, pero parece más claro que la ocupación influye en la percepción de la salud de las personas ancianas, sean éstas varones o mujeres.

Controlando la variable ingresos (tabla 10) (excepto en. la primera categoría, que cuenta con cuatro varones únicamente), las diferencias entre los varones y las mujeres en cuanto a la percepción de la salud no son importantes por categorías de ingresos. Entre los varones apenas se aprecian diferencias en su salud percibida, tengan los ingresos que tengan; únicamente los de más ingresos aparecen claramente en un mejor estado de salud con respecto a los de las otras categorías. En las mujeres tampoco se observa una relación entre los ingresos y salud. No se aprecia una mejoría manifiesta por tener más ingresos, aunque en la categoría de ingresos más altos las mujeres presentan la mejor salud. Eliminada la posible influencia del nivel de ingresos en la percepción de la salud, ser varón o mujer no parece marcar diferencias notables en la salud percibida de las personas ancianas de Bilbao. Por otro lado, el nivel de ingresos únicamente parece influir positivamente en las personas de ingresos más altos que se sienten mejor de salud que las demás personas, y negativamente en las personas de las dos categorías de ingresos más bajos.

Al mantener constante. la variable soledad (tabla 11) no existen diferencias notables de salud percibida por género, excepto entre aquellos/as que experimentan el máximo grado de soledad (aunque el número de varones entre esas personas es muy pequeño: 10 personas). Las diferencias con respecto a las mujeres es alta; ellas se consideran mucho peor que los varones aun sintiéndose todos/as solos/as muchas veces. Las diferencias se aprecian fucrtemente tanto para varones como para mujeres según el grado de soledad manifestado. Incluso las diferencias por género se diluyen. La salud parece 
TABLA 9

Relación entre salud y género, controlando por la ocupación

(En porcentajes)

\begin{tabular}{|c|c|c|c|c|c|c|c|c|c|}
\hline \multirow[b]{3}{*}{ Nivel de salud } & \multicolumn{9}{|c|}{ PERSONAS SEGUN LAS DISTINTAS OCUPACIONES } \\
\hline & \multicolumn{3}{|c|}{$\begin{array}{l}\text { Empresarios/as, } \\
\text { cuadros superiores } \\
\text { altos funcionarios }\end{array}$} & \multicolumn{3}{|c|}{$\begin{array}{l}\text { Empleados/as, } \\
\text { cuadros medios } \\
\text { funcionarios }\end{array}$} & \multicolumn{3}{|c|}{$\begin{array}{l}\text { Trabajadores/as } \\
\text { por cuenta propia }\end{array}$} \\
\hline & Total & Varones & Mujeres & T'otal & Varones & Mujeres & Total & Varones & Mujeres \\
\hline $\begin{array}{lllllll}\text { Enfermos } / \text { as } & \ldots & \ldots & \ldots & \ldots & \ldots & \ldots\end{array}$ & 36 & 33 & 50 & 56 & 56 & 57 & 46 & 40 & 53 \\
\hline $\begin{array}{llllllll}\text { Sanos/as } & \ldots & \ldots & \ldots & \ldots & \ldots & \ldots & \ldots\end{array}$ & 64 & 67 & 50 & 44 & 44 & 43 & 54 & 60 & 47 \\
\hline 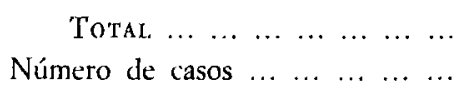 & $\begin{array}{r}100 \\
(14)\end{array}$ & $(12)$ & $(2)$ & $\begin{array}{r}100 \\
(48)\end{array}$ & (34) & (14) & $\begin{array}{l}100 \\
(39)\end{array}$ & $(20)$ & (19) \\
\hline
\end{tabular}

\begin{tabular}{|c|c|c|c|c|c|c|}
\hline \multirow[b]{2}{*}{ Nivel de salud } & \multicolumn{3}{|c|}{$\begin{array}{c}\text { Obreros/as } \\
\text { especializudos }\end{array}$} & \multicolumn{3}{|c|}{$\begin{array}{c}\text { Obreros/as } \\
\text { sin especializar }\end{array}$} \\
\hline & Total & Varones & Mujeres & Total & Varones & Mujeres \\
\hline $\begin{array}{lllllll}\text { Enfermos/as } & \ldots & \ldots & \ldots & \ldots & \ldots & \ldots\end{array}$ & 69 & 68 & 73 & 66 & 59 & 73 \\
\hline $\begin{array}{llllllll}\text { Sanos/as } & \ldots & \ldots & \ldots & \ldots & \ldots & \ldots & \ldots\end{array}$ & 31 & 32 & 27 & 34 & 41 & 27 \\
\hline 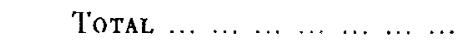 & 100 & & & 100 & & \\
\hline Número de casos $\ldots \ldots \ldots \ldots \ldots$ & $(73)$ & $(62)$ & (11) & $(69)$ & (34) & (69) \\
\hline
\end{tabular}

Fuentl: Encuesta de Ancianos/as de Bilbao 1988. 


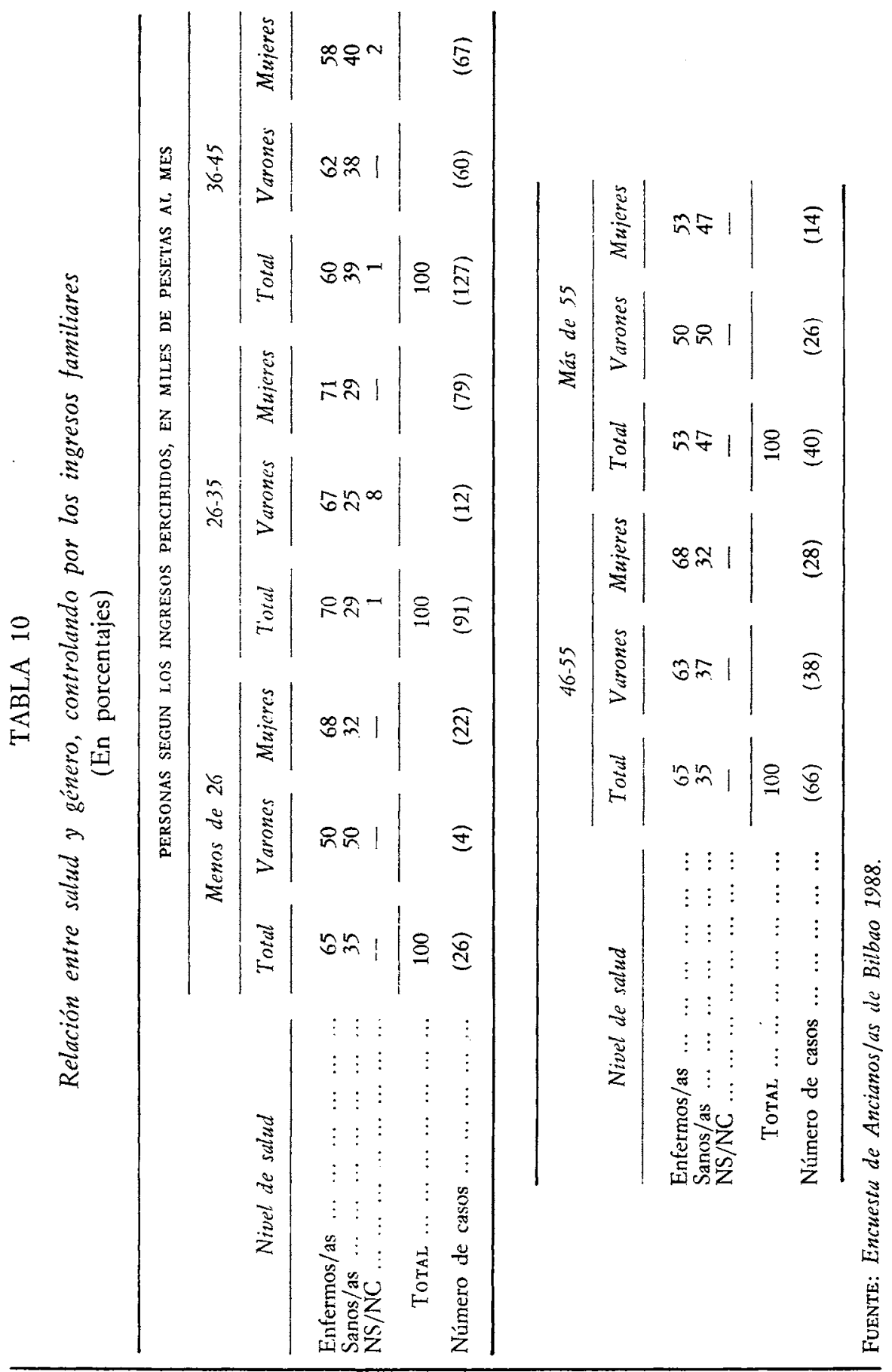




\section{TABLA 11}

Relación entre salud y género, controlando por el sentimiento

de soledad experimentado a lo largo del día

(En porcentajes)

PERSONAS QUE EXPERIMENTAN SOLEDAD SEGUN LA IRECUENCIA

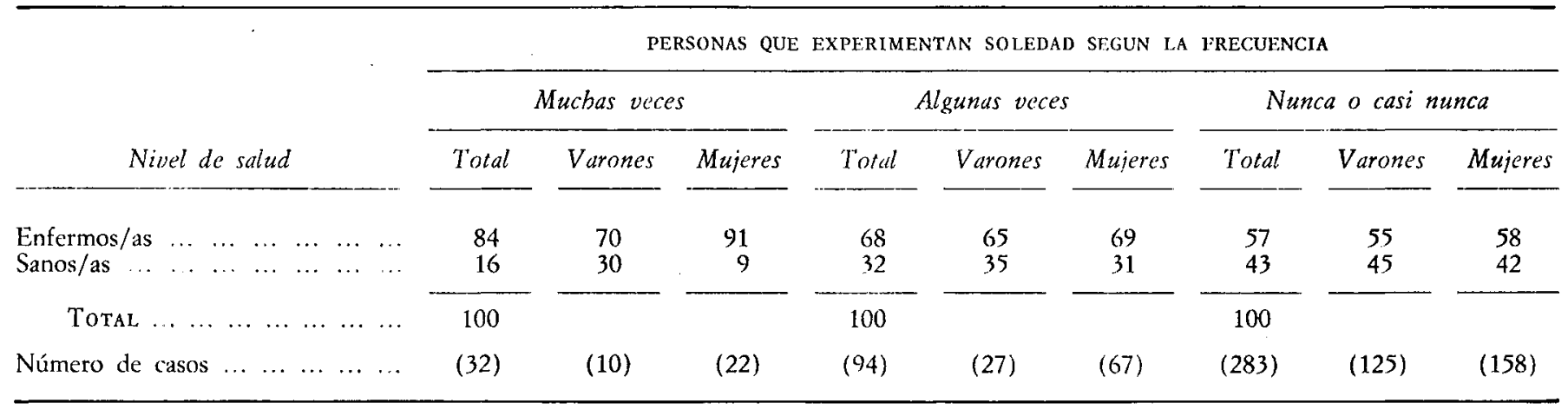

Fuente: Encuesta de Anciunos/as de Bilbao 1988. 
más relacionada con la soledad que con el género. Es más determinante cómo siente un anciano/a su soledad para sentirse mejor o peor de salud (o viceversa) que ser varón o mujer, aunque las mujeres siempre y en todas circunstancias se sienten peor de salud que los varones.

En un primer análisis el género aparecía como la variable discriminante entre las personas ancianas de Bilbao, en cuanto a su salud percibida. Ahora que se ha eliminado la posible influencia de otras variables, no aparece una clara relación entre género y salud. Sin embargo, la ocupación ejercida sí parece tener relación con la salud, tanto en los varones como en las mujeres. Una vez más parece que el estilo de vida asociado al tipo de ocupación ejercida determina no solamente la duración, sino también la calidad de vida de las personas. Pero sobre todo es la soledad la variable que parece mantener una estrecha relación con la salud, sin poderse establecer, al menos por el momento, una relación causal.

Ante la fuerte relación que aparece entre soledad y salud se ha procedido a analizarla controlando las variables género, edad, estado civil, ocupación e ingresos, pero dicotomizando la variable soledad al agrupar las casillas «muchas veces» $y$ «algunas veces». Manteniendo constante la variable género (tabla 12), varones y mujeres se sienten en mejor estado de salud cuando no se sienten solos/as, aunque la diferencia se hace más aguda entre las mujeres, a favor de la mejor salud de las que nunca se sienten solas. Parece que aun siendo más importante la relación entre salud y soledad que entre salud y género, sin embargo, el género parece ejercer cierta influencia, dada la mayor relación existente entre soledad y salud percibida en las mujeres que en los varones.

Al controlar la edad (tabla 13) se aprecian fuertes diferencias entre los/as que se sienten solos y los/as demás, en la percepción de la salud en todos los grupos de edad. Salud y soledad mantienen una fuerte relación, ya que a cualquier edad los más solos/as son los que se sienten más enfermos/as, aunque la soledad influye más a las personas más ancianas, pues las diferencias de porcentajes (tanto en las personas enfermas como en las sanas) con respecto a sentirse o no solas aumentan con la edad. A más edad, tanto enfermas como sanas, se sienten más solas. Analizando el conjunto de los grupos de edad, entre quienes se sienten solos/as no se aprecian diferencias en la percepción de salud por edad; únicamente en aquellos/as de ochenta y cinco y más años se incrementa ostensiblemente la peor percepción. Entre quienes nunca se sienten solos/as tampoco se aprecian por edad diferencias destacables; únicamente entre los más ancianos/as empeora también algo la percepción de salud. Al relacionar salud y soledad, no parece que la influencia de la edad en la salud percibida sea importante, salvo en las personas más ancianas, aunque incluso entre ellas las que no se sienten solas se ven mejor de salud que las otras.

La relación inversa entre edad y salud (a más edad, peor salud) que se 
TABLA 12

Relación entre salud y soledad, controlando por el género (En porcentajes)

PERSONAS CON DIFERENTES GRADOS DE SOLEDAD SEGUN EL GENERO

\begin{tabular}{|c|c|c|c|c|c|}
\hline \multicolumn{3}{|c|}{ Varones } & \multicolumn{3}{|c|}{ Mujeres } \\
\hline Total & $\begin{array}{c}\text { Mucbas y } \\
\text { algunas } \\
\text { veces }\end{array}$ & $\begin{array}{l}\text { Nunca } \\
\text { o casi } \\
\text { nunca }\end{array}$ & Total & $\begin{array}{c}\text { Mucbas y } \\
\text { algunas } \\
\text { veces }\end{array}$ & $\begin{array}{l}\text { Nunca } \\
\text { o casi } \\
\text { nunca }\end{array}$ \\
\hline $\begin{array}{l}58 \\
42\end{array}$ & $\begin{array}{l}67 \\
33\end{array}$ & $\begin{array}{l}55 \\
45\end{array}$ & $\begin{array}{l}64 \\
36\end{array}$ & $\begin{array}{l}75 \\
25\end{array}$ & $\begin{array}{l}58 \\
42\end{array}$ \\
\hline 100 & & & 100 & & \\
\hline (162) & (37) & (125) & $(247)$ & (89) & (158) \\
\hline
\end{tabular}

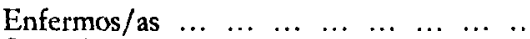

Sanos/as

Total

Nivel de ralud

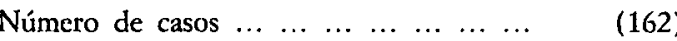

Fuente: Encuesta de Ancianos/as de Bilbao 1988. 


\section{TABLA 13}

Relación entre salud y soledad, controlando por la edad (En porcentajes)

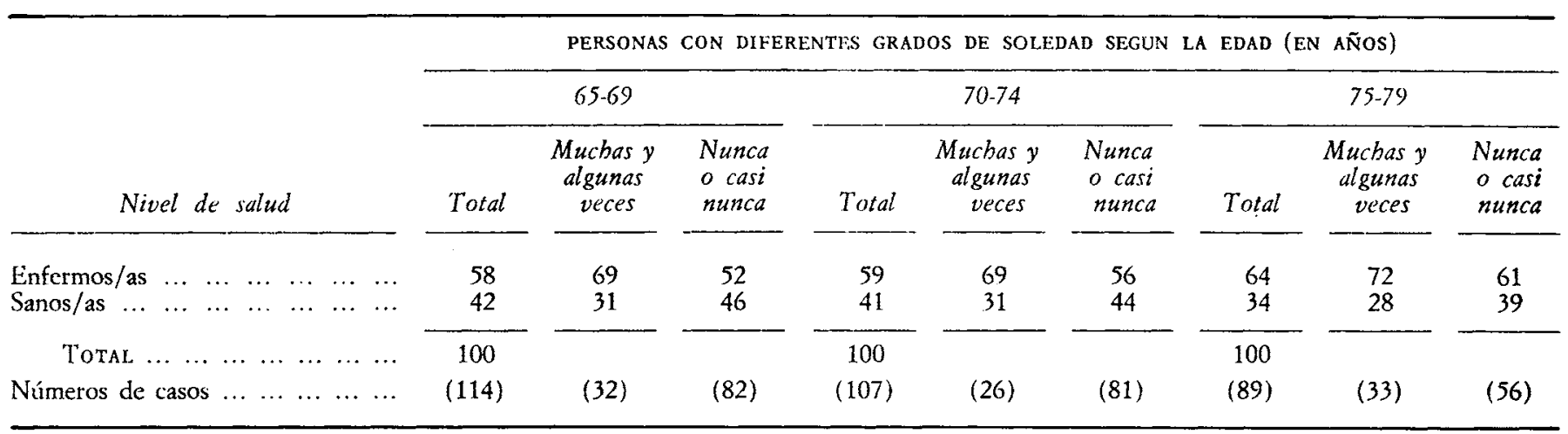

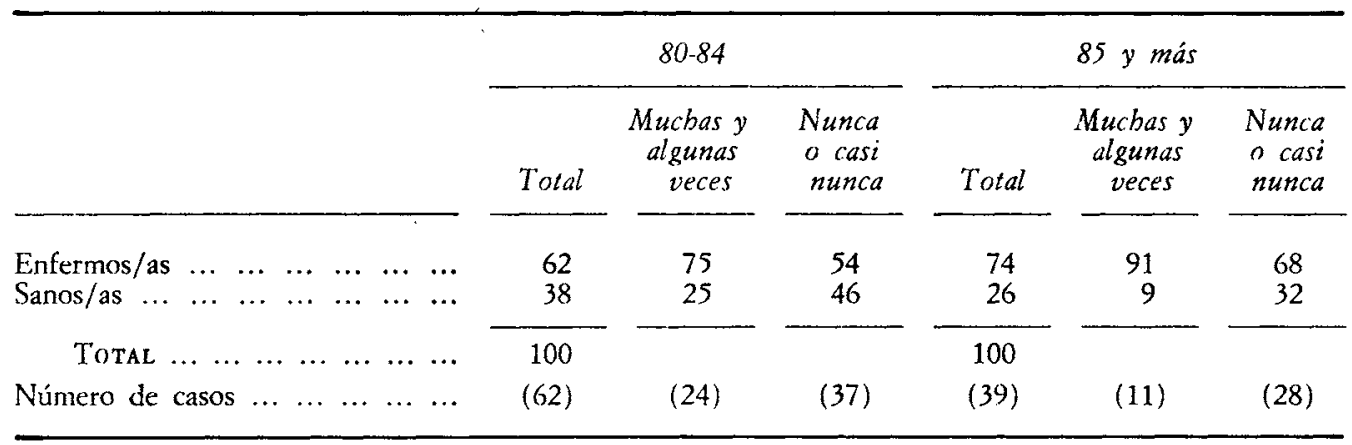

Fuente: Encuesta de Ancianos/as de Bilbao 1988. 
apreciaba en el primer cruce de variables y que se mantiene en buena medida en la anterior neutralización de variables, aparece algo trastocada al tenerse en cuenta la soledad como varhable explicativa. Ciertamente, el grupo de los más ancianos/as manifiesta peor percepción que ninguno de su salud, tanto entre quienes se sienten solos/as como entre quienes no se sienten así. Pero es el grupo en el que más relación se aprecia entre salud y soledad, observándose la mayor diferencia en nivel de salud entre quienes se sienten solos/as. Aunque en la edad más avanzada ésta, con todo lo que conlleva en acumulación de pérdidas, influye en el estado de salud percibida, sin embargo, aparece más fucrte la relación entre soledad y salud que la existente entre edad y salud.

Al controlar por el estado civil (tabla 14) solteros/as, casados/as y viudos/as, muestran diferencias importantes de salud percibida según experimenten o no sentimiento de soledad. Quienes más diferencia muestran son los solteros/as, aunque su representatividad sea menor. Casados/as y viudos/as con efectivos similares muestran parecidas diferencias. De nuevo la soledad aparece como una variable fuertemente relacionada con la salud, independientemente del estado civil. Los casados/as, no obstante, parecen ligeramente más afectados en su salud que los demás cuando se sienten solos/as, aunque la diferencia es pequeña. Puede que la peor soledad sea la expcrimentada en compañía.

Controlando por la ocupación (tabla 15), todas las categorías mantienen diferencias intragrupo en su percepción de salud: entre quienes no se sienten solos/as y quienes se sienten, pero son diferencias variables según las diversas categorías ocupacionales y casi siempre a favor de quienes no se sienten solos/as. Con respecto a quienes se sienten solos/as, la clase alta y los/as autónomos apenas cuentan con efectivos entre las personas solitarias. El 86 y el 90 por 100, respectivamente, no se sienten nunca solos/as. No puede, pues, hab!arse en estos dos casos de diferencias intragrupo en el estado de salud cuando casi ninguno/a declara sentirse solo. Respecto a las otras cuatro categorías, son la de obreros/as cualificados, y la de amas de casa, las ocupaciones menos discriminadas en estado de salud por la variable soledad. La soledad les infiuye en su percepción de la salud algo menos. Estas categorías ocupacionales ejercen también una influencia en dicha percepción.

En cuanto a las diferencias intergrupo de las cuatro categorías, entre las personas que se sienten solas no se aprecian diferencias notables en las distintas categorías. La ocupación parece influir poco en la percepción de la salud. Entre quienes nunca se sienten solos/as en las seis categorías, existen diferencias entre ciertas categorías ocupacionales en cuanto a la salud percibida, resultando más favorecidos (exceptuando la clase alta) los/as trabajadores independientes, empleados/as y obreros/as sin cualificar; quedando en la peor situación las amas de casa y los/as obreros cualificados.

Entre las personas que experimentan sentimientos de soledad, su estado 


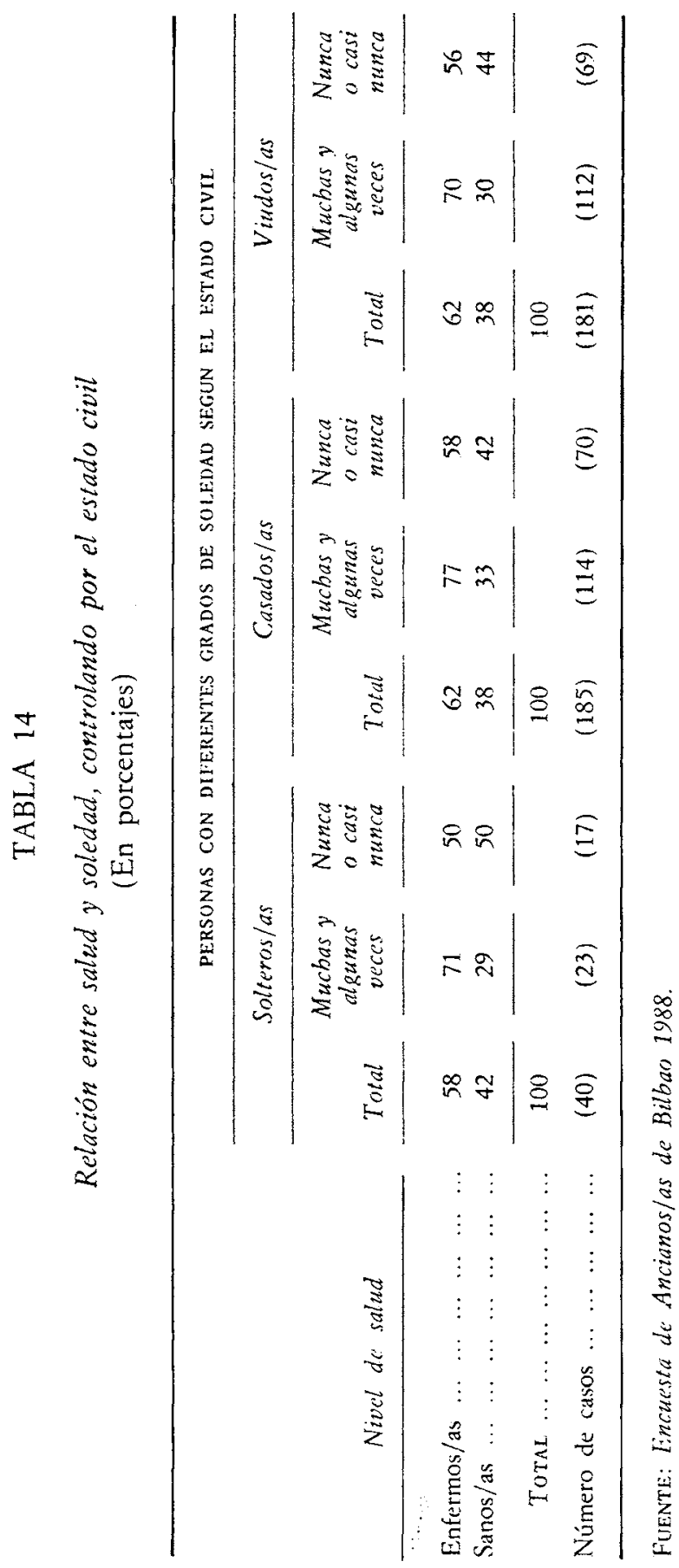


TABLA 15

Relación entre salud y soledad, controlando por la ocupación (En porcentajes)

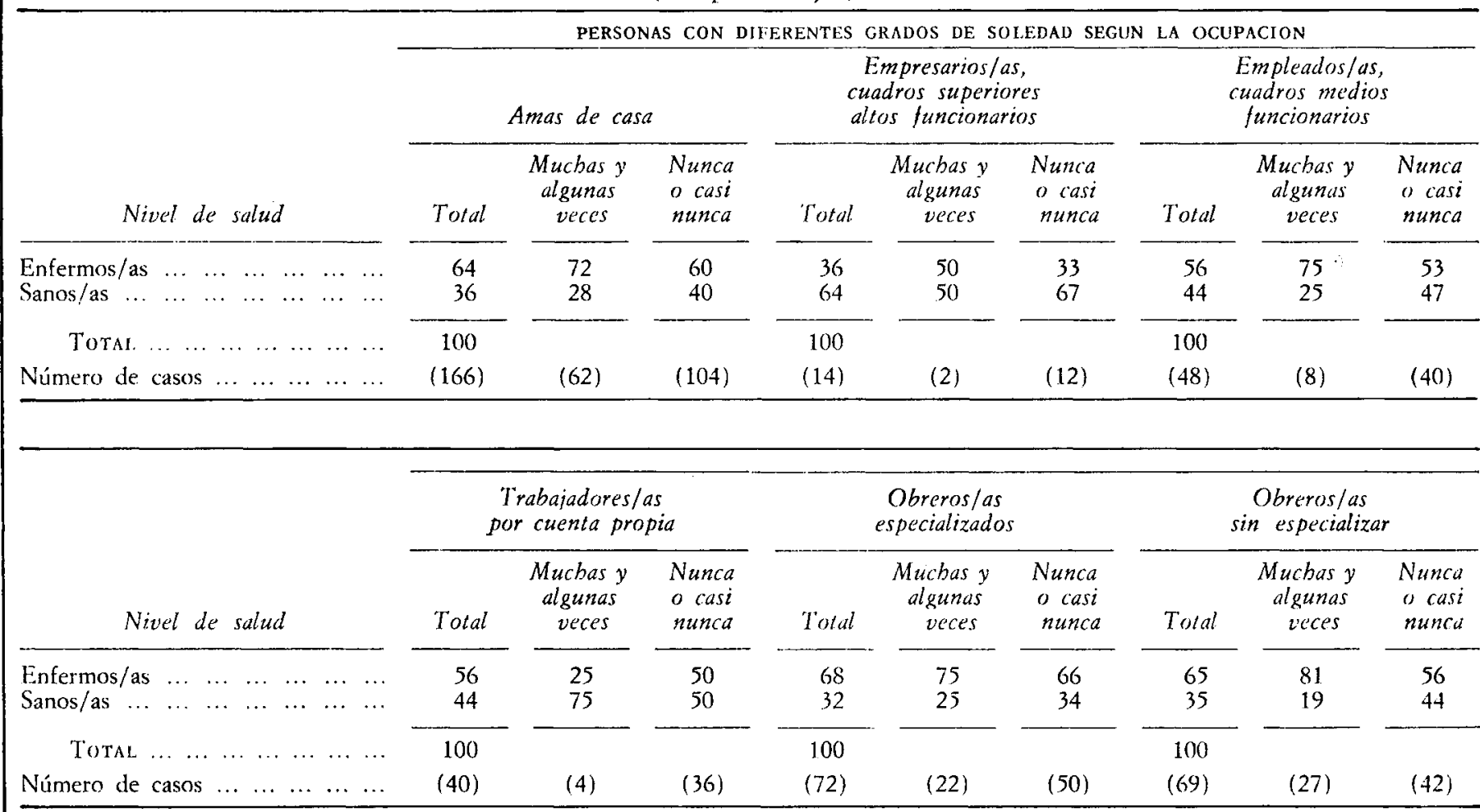

Fufnte: Lincuesta de Ancianos/as de Bilbao 1988. 
de salud depende más de la soledad que de la ocupación ejercida, aunque ésta tenga algo de importancia también. Entre quienes no se sienten solos/as existen diferencias en la salud percibida entre categorías que van desde el 50 por 100 de los/as trabajadores autónomos al 66 por 100 de los obreros/as cualificados ( $\sin$ tener en cuenta por su escasa representatividad sobre el conjunto a la categoría de empresarios). Amas de casa y obreros/as cualificados siguen mostrando peor salud también cuando se introduce en el análisis la variable soledad. La soledad y la salud están relacionadas, pero ciertas ocupaciones también influyen en la percepción de la salud, sobre todo en aquellas personas que nunca se sienten solas. Entre las que se sienten solas, la relación entre ocupación y salud es más débil, es decir, que se sienten mal de salud independientemente de la profesión ejercida. Es más importante su sentimiento de soledad.

Teniendo en cuenta como constante la influencia del nivel de ingresos (tabla 16), las diferencias entre las personas que se sienten solas y aquellas que no se sienten así en nivel de salud son muy acusadas en las dos categorías de ingresos más bajos, haciéndose menores al incrementarse los ingresos. En la categoría de 46.000-55.000 pesetas mensuales, curiosamente, aparecen más enfermas las personas que no se sienten solas. Analizando en todas las categorías de ingresos a aquellas personas que se sienten solas, éstas van teniendo una ostensible mejor percepción de su salud conforme aumentan sus ingresos. En quienes nunca se sienten solos/as no aparece una relación directa entre salud percibida $\mathrm{e}$ ingresos. Estos hallazgos refuerzan la consideración de la soledad como «la complicación más insoportable y más peligrosa de la vejez», ya que "conduce a todas las desesperaciones cuando se acompaña de los problemas financieros, que son el destino de las personas de edad y, sobre todo, de las mujeres solas, demasiado a menudo condenadas a vivir de una miserable pensión de viudedad» (C. Cabirol, 1981: 21). Parece deducirse de lo analizado que entre quienes no se sienten solos/as los ingresos no influyen su percepción de salud; sin embargo, en las personas que se sienten solas -el nivel de ingresos contribuye a mejorar o empeorar su percepción de salud--, la soledad parece influir más que los ingresos. 


\section{TABLA 16}

Relación entre salud y soledad, controlando por los ingresos familiares (En porcentajes)

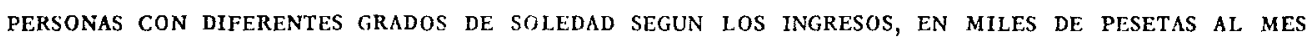

\begin{tabular}{|c|c|c|c|c|c|c|c|c|}
\hline \multicolumn{3}{|c|}{ Menos de 26} & \multicolumn{3}{|c|}{$26-35$} & \multicolumn{3}{|c|}{$36-45$} \\
\hline Total & $\begin{array}{c}\text { Muchas y } \\
\text { algunas } \\
\text { veces }\end{array}$ & $\begin{array}{l}\text { Nunca } \\
\text { o casi } \\
\text { nunca }\end{array}$ & Total & $\begin{array}{c}\text { Muchas y } \\
\text { algunas } \\
\text { veces }\end{array}$ & $\begin{array}{c}\text { Nunca } \\
\text { o casi } \\
\text { nunca }\end{array}$ & Total & $\begin{array}{c}\text { Muchas y } \\
\text { algunas } \\
\text { veces }\end{array}$ & $\begin{array}{l}\text { Nunca } \\
\text { o casi } \\
\text { nunca }\end{array}$ \\
\hline $\begin{array}{l}68 \\
32\end{array}$ & $\begin{array}{l}83 \\
17\end{array}$ & $\begin{array}{l}56 \\
44\end{array}$ & $\begin{array}{l}71 \\
29\end{array}$ & $\begin{array}{l}85 \\
15\end{array}$ & $\begin{array}{l}61 \\
39\end{array}$ & $\begin{array}{l}60 \\
40\end{array}$ & $\begin{array}{l}68 \\
32\end{array}$ & $\begin{array}{l}57 \\
43\end{array}$ \\
\hline $\begin{array}{r}100 \\
(28)\end{array}$ & (12) & (16) & $\begin{array}{r}100 \\
(91)\end{array}$ & $(40)$ & $(51)$ & $\begin{array}{c}100 \\
(127)\end{array}$ & (39) & $(88)$ \\
\hline
\end{tabular}

\begin{tabular}{|c|c|c|c|c|c|c|}
\hline \multirow[b]{2}{*}{ Nivel de salud } & \multicolumn{3}{|c|}{$46-55$} & \multicolumn{3}{|c|}{ Más de 55} \\
\hline & Total & $\begin{array}{c}\text { Muchas y } \\
\text { algunas } \\
\text { veces }\end{array}$ & $\begin{array}{c}\text { Nunca } \\
\text { o casi } \\
\text { nunca }\end{array}$ & Total & $\begin{array}{c}\text { Mucbas y } \\
\text { algunas } \\
\text { veces }\end{array}$ & $\begin{array}{l}\text { Nunca } \\
\text { o casi } \\
\text { nunca }\end{array}$ \\
\hline 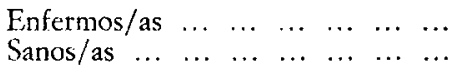 & $\begin{array}{l}65 \\
35\end{array}$ & $\begin{array}{l}57 \\
43\end{array}$ & $\begin{array}{l}67 \\
33\end{array}$ & $\begin{array}{l}53 \\
47\end{array}$ & $\begin{array}{l}57 \\
43\end{array}$ & $\begin{array}{l}52 \\
48\end{array}$ \\
\hline $\begin{array}{rrrrrrr}\operatorname{Total} & \ldots & \ldots & \ldots & \ldots & \ldots & \ldots \\
\text { Número de } \operatorname{casos} & \ldots & \ldots & \ldots & \ldots & \ldots\end{array}$ & $\begin{array}{r}100 \\
(66)\end{array}$ & (14) & (52) & $\begin{array}{r}100 \\
(40)\end{array}$ & (7) & (33) \\
\hline
\end{tabular}

Fuente: Encuesta de Ancianos/as de Bilbao 1988. 


\section{REFERENCIAS BIBLIOGRAFICAS}

BESDINE, Richard (1988): «Older but coming on strong», Time, 8, pp. 48-50.

BRODY, J. A. (1982): «Influences psychosociales sur le vieillissement», pp. 191-196. en Xème. Contérence International de Gérontologie Sociale, París: Centre International de Gérontologic Sociale, pp. 192-193.

Cabirol, Claude (1981): La condition des personnes âgées, Toulouse: Privat, $139 \mathrm{pp}$.

Camprell, Angus (1981): Tre Sense of Woll-Being in America: Recent Patterns and Trends, Nucva York: McGraw-Hill Book, 253 pp.

Cox, Harold (1984): Later Life: The Realities of Aging, Nueva Jerscy: Prentice-Hall, $365 \mathrm{pp}$.

Grandall, Richard G. (1980): Gerontology: A Bebavioral Science Approach, Nueva York: Newbery Award Records, 571 pp.

Marshall, Victor W. (1982): «La santé des grands viellards sujet de préocupation de leurs enfants», pp. 99-110, en Xème. Conférence Internationale de Gérontologie Sociale, vol. 2, París: Centre International de Gérontologie Sociale, p. 103.

MCKAIN, Walter (1969): «Family patterns in later life», pp. 171-196, en H. Cox, Later Lite: The Realities of Aging, Nueva Jersey: Prentice-Hall.

Miguel, Jesús M. de (1985): La salud pública del futuro, Barcelona: Ariel, 274 pp.

Miguel, Jesús M. de, y Díez Nicolás, Juan (1985): Políłicas de población, Madrid: Espasa-Calpe, $300 \mathrm{pp}$.

Neughrten, B. (1988): «Older, but coming on strong», Time, 8, pp. 48-50.

PAlmore, E. (1976): «Physical health», pp. 150-177, en R. G. Grandall, Geroniology: A Bebavioral Science Approach, Nueva York: Newbery Award Records, p. 156.

Williamson. John B. (1980): Aging and Society: An Introduction to Social Gerontology, Nueva York: Holt, Rinehart y Winston, 450 pp. 
NOTAS DE INVESTIGACION 